\section{Are the Proton Pump Inhibitor-Responsive and-Nonresponsive Phenotypes of Eosinophilic Esophagitis Exactly the Same?}

Gómez Torrijos $\mathrm{E}^{1}$, Castro Jimenez A ${ }^{1}$, Gratacós Gómez AR ${ }^{2}$, González Jimenez $\mathrm{OM}^{1}$, Joyanes Romo JB${ }^{1}$, Feo Brito $\mathrm{F}^{1}$, Urra Ardanaz $\mathrm{JM}^{3}$, Garcia Rodriguez $\mathrm{R}^{1}$

${ }^{1}$ Allergy Section, Hospital General Universitario, Ciudad Real, Spain

${ }^{2}$ Facultad de Medicina, Universidad de Castilla La Mancha, Ciudad Real, Spain

${ }^{3}$ Immunology Section, Hospital General Universitario, Ciudad Real, Spain

J Investig Allergol Clin Immunol 2021; Vol. 31(5): 441-442 doi: 10.18176/jiaci.0666

Key words: Eosinophilic esophagitis. Phenotypes. Proton pump inhibitor. Allergic characteristics. Atopic comorbidities.

Palabras clave: Esofagitis eosinofílica. Fenotipos. Inhibidor de la bomba de protones. Características alérgicas. Comorbilidades atópicas.

A new conceptual definition of eosinophilic esophagitis (EoE) was proposed in the 2011 consensus, and a new potential disease phenotype, proton pump inhibitor-responsive esophageal eosinophilia (PPI-REE) was also recognized [1]. EoE was defined as an antigen-driven condition characterized clinically by symptoms of esophageal dysfunction and histologically by $\geq 15$ eosinophils per high power field (HPF). Diagnosis is based on a comprehensive assessment of non-EoE disorders that could cause esophageal eosinophilia [2]

EoE and PPI-REE were considered separate clinical entities, as they responded differently in the PPI trial. The experts subsequently proposed not including responsiveness to a PPI as a diagnostic criterion and, consequently, avoiding the term PPI-REE for patients with an EoE phenotype and both a histological and a clinical response to PPI therapy [3]. The most recent recommendation is to refer to these 2 phenotypes as responding EoE (R-EoE) and nonresponding EoE (NR-EoE).
Although not all experts agree, recent and evolving evidence, mostly from adults, shows that PPI-REE and EoE patients are clinically, endoscopically, and histologically indistinguishable, with features of $\mathrm{T}_{\mathrm{H}} 2$ immune-mediated inflammation and gene expression [3]. A Spanish study concluded that both phenotypes of EoE share sensitization profiles with only slight differences [4].

Few studies assess whether both phenotypes (R-EoE and NR-EoE) are identical in allergic characteristics and atopic comorbidities. The objectives of this study were to study the similarities and differences between the 2 phenotypes in terms of allergic characteristics and atopic comorbidities.

We performed a prospective observational study that included patients diagnosed with EoE (symptoms of esophageal dysfunction and $\geq 15 / \mathrm{HPF}$ in at least 1 esophageal biopsy) between 2013 and 2018. All patients completed 2 months of treatment with omeprazole $40 \mathrm{mg}$ twice daily and underwent esophagoscopy with excisional biopsies to determine whether the EoE had remitted with PPI therapy.

We assessed a series of variables for both subgroups (R-EoE and NR-EoE), as follows: skin prick tests (SPT) for aeroallergens (mites, fungi, epithelia, and pollens) and foods (wheat, cow milk, eggs, lentils, peanuts, hake, and shrimp), total IgE, specific IgE (sIgE) to the abovementioned foods, eosinophils in peripheral blood (EPB), eosinophil cationic protein, atopy (at least 1 positive allergological test result [SPT $>3.3 \mathrm{~mm}$ or $\left.\operatorname{sIgE}>0.35 \mathrm{kU}_{\mathrm{A}} / \mathrm{L}\right]$ ) and atopic comorbidities such as atopic dermatitis, rhinoconjunctivitis, bronchial asthma, and IgE-mediated food allergy.

The statistical analysis was performed using SPSS and involved a comparison of both groups based on the test (quantitative variables) and the $\chi^{2}$ test (qualitative variables), since patient samples from both phenotypes followed a normal distribution.

Treatment with omeprazole was prescribed to 203 patients diagnosed with EoE, although 27 were withdrawn for breach of protocol or refusal to undergo esophagoscopy. EoE remitted in only 55 patients $(31.25 \%)$.

Significant differences were found between the groups in the following variables: tests with animal dander $(P=.025)$, sIgE to cow milk $(P=.045)$, IgE-mediated food allergy $(P=.024)$, EPB $(P=.021)$, atopy $(P=.002,50 \%)$, and atopic comorbidities $(P=.001)$ (Table). We did not find significant differences between the 2 phenotypes in sensitization to the

Table. Statistically Significant Differences Between 2 Subgroups of Patients with EoE

\begin{tabular}{lccc}
\hline & EoE unresponsive & EoE responsive & $P$ Value $^{\mathrm{a}}$ \\
& to PPI & $25 \%$ & .025 \\
Skin prick test (positive to epithelia) & $43.8 \%$ & 0.24 & .045 \\
sIgE to cow milk, kU/L & 0.54 & $12 \%$ & .024 \\
Food Allergy & $29.6 \%$ & $250.75(\mathrm{X})$ & .021 \\
Eosinophils in peripheral blood/ $\mu \mathrm{L}$ & $323.66(\mathrm{X})$ & $50 \%$ & .002 \\
Atopy & $75 \%$ & $52.2 \%$ & .001 \\
Atopic comorbidities & $77.6 \%$ & & \\
\hline
\end{tabular}

Abbreviations: EoE, eosinophilic esophagitis; PPI, proton pump inhibitor; X, arithmetic mean.

a Statistical significance was set at $P<.05$. 
remaining aeroallergens and other foods, except for egg, which was at the limit of statistical significance.

Although most experts in EoE agree that the management of this disease should be multidisciplinary [5], very few studies examine the allergological characteristics in both EoE phenotypes, probably, because the experts did not consider it relevant. Nevertheless, it is known that atopic comorbidities (atopic dermatitis, rhinoconjunctivitis, bronchial asthma, and IgE-mediated food allergy) are positively associated with EoE, which may be a late manifestation of the allergic march [6].

There were no significant differences between patients with R-EoE and those with NR-EoE regarding total IgE or sensitization to aeroallergens except for sensitization to animal dander and cow milk. If we compare our results with those of a study in a Japanese population [7], where the authors compared total IgE level in both EoE phenotypes, we find differences in the levels of this biomarker, namely, higher levels in NR-EoE; The reasons for this difference with our results could be that the number of patients in our study is much smaller and the authors of the Japanese study do not specify whether patients were sensitized to seasonal or perennial aeroallergens.

Sensitization to pollen was the most frequent type in the cases we studied, although we did not find differences for this variable between the subgroups. Our results agree with those of other published studies [8], probably because levels of grass pollens and olive trees in spring are very high in the area where the patients live.

The differences in SIgE levels to cow milk support a higher atopic burden in patients with R-EoE. In addition, Hill et al [6] found that bronchial asthma and IgE-mediated food allergy were independently and cumulatively associated with more frequent diagnoses of EoE.

A study performed in the USA several years ago revealed no differences for total IgE level [9], although the authors did find statistically significant differences in the EPB count, which was greater in the NR-EoE subgroup. These results agree with ours and with those of the abovementioned Japanese study [7].

IgE-mediated food allergy was more frequent in patients with NR-EoE, both in our study and in the Japanese one. We found that patients with NR-EoE also have more atopic comorbidities, while in the Japanese study, the authors found that only bronchial asthma was more common in the NR-EoE subgroup [7].

In studies carried out by allergists, the percentage of patients with R-EoE is lower than in studies carried out by gastroenterologists [10], probably because patients referred from primary care to allergology are more frequently atopic than those referred to specialties such as pediatrics and/or gastroenterology.

This study compares atopic characteristics and comorbidities between the 2 subgroups of EoE discussed. The results suggest that both phenotypes may not be the same: allergic sensitizations and comorbidities seem to be more frequent in the NR-EoE phenotype. However, more studies with larger samples are needed to confirm these results.

We conclude that the NR-EoE phenotype is characterized by a higher degree of atopy.

\section{Funding}

The authors declare that no funding was received for the present study.

\section{Conflicts of Interest}

The authors declare that they have no conflicts of interest.

\section{References}

1. González-Cervera J, Lucendo AJ. Eosinophilic Esophagitis: An Evidence-Based Approach to Therapy. J Investig Allergol Clin Immunol. 2016;26(1):8-18

2. Orden Izquierdo E, Gutiérrez Junquera C, Mahillo-Fernández I, Subiza Garrido-Lestache J, Román Riechmann E. Increasing Incidence of Pediatric Eosinophilic Esophagitis in the Southwest of Madrid, Spain. J Investig Allergol Clin Immunol. 2019;29(1):24-9

3. Molina-Infante J, Bredenoord AJ, Cheng E, Dellon ES, Furuta ES, Gupta SK, et al. Proton Pump Inhibitor-Responsive Oesophageal Eosinophilia: An Entity Challenging Current Diagnostic Criteria for Eosinophilic Oesophagitis. Gut. 2016;65(3):524-31.

4. Lluncor $M$, Pedrosa $M$, Cancelliere $N$, Rivero-Paparoni $D$, Burgos A, Fiandor A, et al. Molecular Sensitization Profile According to Proton Pump Inhibitor Response in Patients With Esophageal Eosinophilia. J Investig Allergol Clin Immunol. 2018;28(5):354-8

5. Reed CC, Dellon ES. Eosinophilic esophagitis. Med Clin North Am. 2019;103(1):29-42.

6. Hill DA, Grundmeier RW, Ramos M, and Spergel JM. Eosinophilic Esophagitis is a Late Manifestation of the Allergic March. J Allergy Clin Immunol Pract. 2018;6(5):1528-33.

7. Jiao D, Ishimura $N$, Maruyama $R$, Ishikawa $N$, Nagase $M$, Oshima $N$, et al. Similarities and differences among eosinophilic esophagitis, proton-pump inhibitor-responsive esophageal eosinophilia, and reflux esophagitis: comparisons of clinical, endoscopic, and histopathological findings in Japanese patients. J Gastroenterol. 2017;52:203-21.

8. Letner D, Farris A, Khalili H, Garber J. Pollen-food allergy syndrome is a common allergic comorbidity in adults with eosinophilic esophagitis. Dis Esophagus. 2018;31(2):10.

9. Dellon ES, Speck O, Woodward K, Gebhart JH, Madanick RD, Levinson $S$, et al. Clinical and endoscopic characteristics do not reliably differentiate $\mathrm{PPI}$-responsive esophageal eosinophilia and eosinophilic esophagitis in patients undergoing upper endoscopy: A Prospective Cohort Study. Am J Gastroenterol. 2013;108(12):1854-60.

10. Gómez-Torrijos $E$, García-Rodríguez $R$, Castro-Jiménez $A$, Rodríguez-Sanchez J, Méndez Díaz Y, Molina-Infante J. The efficacy of step-down therapy in adult patients with proton pump inhibitor-responsive oesophageal eosinophilia. Aliment Pharmacol Ther. 2016;43(4):534-40.

- Manuscript received October 8, 2020; accepted for publication January 5, 2021.

Elisa Gómez Torrijos

C/Obispo R. Torija s/n

13005 Ciudad Real Spain

E-mail: egomezt.cr@gmail.com 